\title{
INFLUÊNCIA DA MATÉRIA ORGÂNICA NA ATIVIDADE MICOBACTERICIDA DO HIPOCLORITO IDE SÓDIO COMERCIAL COM 2,5\% DE CLORO ATIVO*
}

\author{
INFLUENCE OF ORGANIC SOIL. ON THE MYCOBACTERICIDAL. \\ ACTIVITY OF THE COMMERCIAL SODIUM HYPOCHLORITE WITH 2.5\% OF ACTIVE CHLORINE
}

\author{
Andrea(astillo (GUERRER()'; Sonia Regina PINHEIRO); Zenáide Maria de MORAIS'; \\ Silvio Arruda VASCONCELL.OS`; Eumio Honma I'TO': .José Soares FERREIRA NETOS
}

\begin{abstract}
RESUMO
Foi investigada a maior diluição do hipoclorito de sódio comercial com 2.5\% de cloro ativo (água de lavadeiral) capaz de inativar o Mycobacterium fortuitum em presença de níveis variáveis de fezes de bovino como fonte de matéria orgânica. Os ensaios foram conduzidos de modo que o desinfetante atuasse durante 60 minutos à temperatura de 4 a $8^{\circ} \mathrm{C}$. A neutralização da ação do desinfetante foi obtida com a solução de tiossullato de sódio a $0.5 \%$ e tween-80 a $0.05 \%$ ( $\mathrm{v} / \mathrm{v})$. Os microrganismos sobreviventes foram recuperados em meio de LowensteinJensen. A quantificação dass unidades formadoras de colônias (L.F.C.) foi analisada pelo Teste "U" de Mann-Whitney. ()s resultados obtidos demonstraram que a presença de fezes bovinas prejudicou a atividade micobactericida do desinfetante ensaiado. Foi possivel constatar-se que as diluições de trabalho capazes de determinar a redução de 70\% do número de L.F.C. foram de I:64 e 1:16. respectivamente. cm ausência e presença de matéria orgânica. Em diluiçōes de trabalho superiores alo valor de 1:64 a atividade micobactericida do hipoctorito de sódio foi muito irregular.
\end{abstract}

UNITIR.MOS: Desinfeção: Micobacléria: Hipoclorilo de sódio

\section{INTRODU(Ċ̃O)}

Dentre os diversos grupos de desinletantes químicos disponíveis para uso pecuário os produtos liberadores de cloro nascente têm tido grande aplicação, pois reunem as características de haixa toxicidade, pequena ação corrosiva, baixo custo e grande disponibilidade. o que os recomenda inclusive para o tratamento da água de bebida e de materiais que possam entrar em contato com os allimentos 1.46.9.13.15.23.

COSTIGAN" (1936) verilicou que as soluções de hipocloritos com baixa alcalinidade, contendo 50 partes por milhão de cloro ativo foram capares de destruir o Mycobacterium tuberculosis e que esta característica apresentava associação positiva com o aumento de temperatura na laixa de 50 a $60^{\circ} \mathrm{C}$ positivo.

SALRAT e LAUTIÉ:" (1960) estudaram a ação de desinlelantes quimicos sobre o Mycobacterium tuberculosis. concluindo cue a cepa utilizada, o grau de umidade do meio e a presença de matéria orgânica afelavam os resultados dos ensaios. Dentre os produlos testados por estes autores. os hipocloritos com 1.0\% de cloro ativo foram os que apresentaram maior poder micobactericida.

SMITH $^{21}$ (1968) citado por RLBIN ${ }^{17}$ (1983), comlirmou o poder micobactericida do hipoclorito de sódio em presença de catarro e HOFFMAN et al. "(1981) destacaran que dentre os fatores que influenciam a atividade bactericida dos compostos clorados. a presença da matéria orgânica como lezes. urina ou sangue assume uma importância capital pois estes consomem o cloro ativo e provocam uma redução da atividade germicida do desinfetante.

GÉLINAS L GOULET ${ }^{*}$ ( 1983 ) ressaltaram a grande inibição da ação bactericida do hipoclorito de sódio ocasionada pela presença de matéria orgânica, destacando também a importância do tipo de contaminante orgânico; no entanto, não investigaram a influência de fezes de animais como fonte de matéria orgânica.

WANG ier al. ${ }^{25}$ ( 1983 ) conluíram que a ação micobactericida do hipoclorito de sódio foi fortemente influenciada pela concentração do desinfetante, pelo número de micobactérias

\footnotetext{
- Médica Velerinário - Ministério da Agricultura da Répública Dominicana

2. Prolesser Assistente Faculdade de Medicina Veterindíria L Zenotecnia da USP

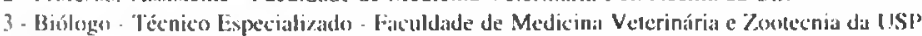

4. - Professor Associado - Fakuldade de Medicina Veterintiria e Zuotecnia da USP

5- Proficusor Doutor - I'aculdade de Medicina Veterinárial è \%orstecenial da USP

* Dissereçâo de Mestrado apresentada à faculdade de Medicina Velerinária e Zootecnia da LSP

Trabalho conduzide com o apoio da liAPESP. Processo M)/2059-9.
} 
e também pela presenç̧a da matéria orgânicaı, particularmente. durante a fase de interação desinfetantc-bactéria.

VI:RA et al. "(1985) verificaram que os produtos clorados (Cal clorada e hipoclorito de cálcio) com $5.0 \%$ de cloro inativaram o Mycobacterium bovis em presença de 0,3 gramas de fe\%es bovina como lonte de matéria orgânica. após três horas de contato à temperatura de $22-24^{\circ} \mathrm{C}$.

PINHIIRO "1" (1990) estudou a intluêncial da matéria orgânica na atividade micobactericida de cinco desintetantes químicos de uso pecuário, constatando que o hipoclorito de sódio (água de lavadeira) com $2.5 \%$ de cloro ativo, diluído na proporção) de 1:8 foi o melhor dos cinco produtos testados. Neste experimento a Autora trabalhou com Mycobacterium fortuitum. cmpregou uma hora de contato entre o microrganismo o o desintetante. utilizou a faixa de temperatura de 4 a $8 " \mathrm{C}$ positivos e 0.5 gramas de lezes de bovino como fonte de maltćria orgânica.

Tendo em vista a excelente atividade micobactericida obtida nas condiçōes estabelecidas por PINHFIRO ${ }^{16}(1990)$. foi delincado () presente (rabalho que se propôs a estender tais conclusões, decerminando a maior diluição do hipoclorito de sódio com 2,5\% de cloro ativo capaz de inativar o Mycobacterium fortuitum fiente a niveis variáveis de fezes bovinas como fonte de malćria orgânica.

\section{MATERIAL, E ME'TOIOO}

() microrganismo leste foi uma culura de Mycobacterium fortuitum **.com sele dias de cultivonomeiode l.owensteinJensen diluido a (0.0()(0).5g/\% (peso úmido) $1 \%$ em solução salina estéril $0.85 \%$.

A matéria orgânica tratada foi representada por fezes de bovinos provenientes de animais submelidos a controle de tuberculose, colhidas diretamente do reto dos mesmos. submetidos à ação do vapor lluente durante 30 minutos e armazenadas à temperatura de $20^{\circ} \mathrm{C}$ negativos em alíquotas de $0.5 ; 1,0 ; 1.5 ; 2.0$ gramas até o momento da utilização. A ausência de Mycobacterium sp nas fexes foi comprovada através da cultura em lowenstcin-Jensen e Stonebrink e Lesslic ${ }^{2}$ após incubação em caldo de soja tripticase**: (TSB) a $37^{\circ} \mathrm{C}$ por seis horas ${ }^{14} \mathrm{c}$ a descontaminação segundo a técnica de Petrotl?

O carreador utilizado foi uma folha de papel de filtro do tipo xarope, com $50 \mathrm{~cm}$, gramatura de $2.50 \mathrm{~g} / \mathrm{m}$. cortada em

\footnotetext{
** Obtida junto ao Instituto Biológico de São Paulo

*** MFRCK
}

formato circular e com um diâmetro de $9.5 \mathrm{~cm}$, na qual foram desenhadas com grafite. aleatoriamente, tres círculos com? cm de diâmetro.

O suporte para a condução dos ensaios toi uma placa de Petri com $9,5 \mathrm{~cm}$ de diâmetro (áréa inlerna de $70,882 \mathrm{~cm}$ ).

A solução neutralizante utilizada para sustar o cleito do desinlelante foi a solução de liossulfalo de sódio al $0.5 \% \mathrm{p} / \mathrm{s}$ acrescido de $0.05 \% \mathrm{w}$ de lween/ $/ 80 * 2 * 2 \%$.

O desinfelante empregado foi o hipoclorito de sódio comercial (água de lavadeira) eom 2.5\% de cloro ativo. diluído nas proporçôes de 1:16: 1:32; 1:64: 1:128 e 1:256. O diluente do desinfetante foi água não submetida a tratamento químico. bidestilada em equipamento de vidro. submetida a autoclavação durante 1.5 minutos a $121^{\circ} \mathrm{C}$ c armasenada à temperatura de refrigetação.

A quantilïcaçãa) das unidades formadoras de colonias (U.F.C.) foi execulada como preconizado por PINHFIRO "a $(190(0)$. demarcando-se uma áreat da superficie do meio de cultura. contando-se $6 \mathrm{em}$ a partir da extremidade interior na superfície expostat. Lendo a keitura obedecido o seguinte critério:

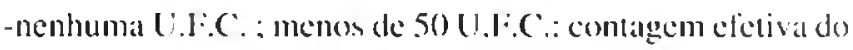

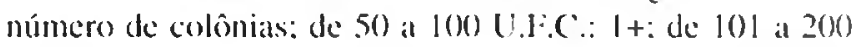

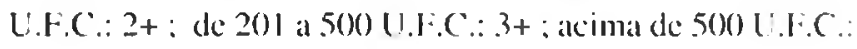
$4+$

A análise dos resultados obtidos foi efetuada atratés de teste não-paramétrico, para comparação de duas amostras independentes: Teste U de Mann-Whitney ". () nivel de significâncià adotado foi de (0,05. () cocticiente de variaçăo das contagens de L.F.C. foi calculado através da fórmula indicada por SOUNIS $=(1972)$.

Em cada ensaio foram testadas 5 diluiçôes diferentes de hipoclorito de sódio e um grupo controle no qual o produto químico foi substitúdo pelo placebo (solução salinat estéril). Além destes grupos houve um controle onde a matéria orgânica foi substituída por solução salina estéril.

Sobre o carreador de papel de fïtro foram colocados quatro mililitros da suspensão de Mycobacterium fortuitum 0.0005 $\mathrm{g} / \%{ }^{19}$, distribuídos uniformemente por loda a área exposta do carreador. A seguir foram colocadas as fezes de acordo con as quantidades pré-estabelecidas (0,5; 1,0) 2.0 gramas) as quais foram distribuidas uniformemente por toda a superfícic da placa. No grupo controle substituiu-se a matéria orgânica por solução salina estéril em volumes de 1,$0 ; 2,0 ; 3.0$ e 4.0 mililitros, respectivamente, segundo as diterentes quantida- 


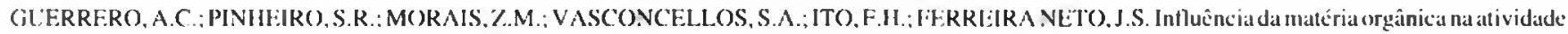
micobactericida do hipexiorito de sódio conercial com 2.5\% de cloro ativo. Bras. J. vet. Res. anim. Sci., São Paalo, v.30, p.211-6, 1993. Suplemento.

des de matéria orgânica utilizadas.

As placas foram armazenadas a uma temperatura de $28^{\circ} \mathrm{C}$ durante 30 minutos. Uma vez concluído este período foram aplicados os 4 mililitros do hipoclorito de sódio nas respectivas concentrações.

O período de atuação do desinfetante foi de 60 minutos, nos quais as placas foram mantidas à temperatura de 4 a $8^{\circ} \mathrm{C}$. A seguir, dos carreadores foram recortados três amostras circulares com $2,0 \mathrm{~cm}$ de diâmetro as quais loram maceradas com graal e pistilo/estéreis, e 10 mililitros da soluçãoneutralizante; esta suspensão foi tamizada e submelida a uma nova diluição de razão de de\%, modo a obter-se uma suspensão a $1: 100^{\text {th }}$. Esta foi centrifugada a 1000 (i durante 20 minutos. Desprezou-se o sobrenadante e ressuspendeu-se o sedimento com I mililitro de solução salina estéril a $0.85 \%$, e foram semeados cinco tubos com meio de cultura Lowenstein-Jensen ${ }^{2}$. Estes tubos foram incubados à temperatura de $37^{\circ} \mathrm{C}$ por um período de sete dias. Transcorridos os sete dias de incubação foi observada a presença de colônias e nos casos positivos, a confirmação da característica de álcool-ácido e a resistência do bacilo isolado foi obtida com a coloração de ZichelNeelsen ${ }^{2}$.

As leituras foram realizadas com sete dias de incubação a $37^{\circ} \mathrm{C}$. em uma área calculada a partir de seis centímetros lineares medidos na superfícic exposta do meio de cultura, registrando-se os números de Unidades formadoras de Colónias (U.F.C.) conforme os critérios apresentados a seguir: $=0,0$ colônias: ()$=$ contagem real: $1+=75,0$ colonias; $1 / 2+=112,5$ colônias: $2+=150,0$ colônias; $2 / 3+=$ 250.0 colônias; $3+=350$ colônias: $3 / 4+=425,()$ colônias; $4+$ $=500,0$ colonias.

\section{RESULTAIOS}

Os resultados obtidos estão condensados nas Tab. 1 a 4 e que apresentam valores expressos em percentuais de redução do número de U.F.C. de Mycobacterium fortuitum por tratamento (diluição do desinletante e presença de matéria orgânica) $\mathrm{em}$ relação aos respectivos controles $\mathrm{em}$ cada grupo experimental.

Tomando-se como valor mínimo desejável para a mensuraçāo da ação micobacteriana de um desinfetante a redução de pelo menos $70 \%$ do número de colônias obtido nos respectivos controles, verifica-se que em ausência de matéria orgânica este limiar é obtido de maneira consistente até a diluição do hipoclorito de sódio de 1:64; no entanto, em presença de matéria orgânica isto só ocorre para o hipoclorito de sódio diluído na proporçāo de $1: 16$, frente a 0,$5 ; 1,0$ e 1,5 gramas de matéria orgânica (Tab. 1 a 3). Saliente-se, inclusive, que para

\section{TABELA 1}

Percentagem de redução de Unidades formadoras de Colônias (U.F.C.) de Mycohacterium fortuitum em relação ao grupo controle, segundo a concentração de hipoclorito de sódio com $2.5 \%$ de cloro ativo, a condição de tratamento com $0.5 \mathrm{~g}$ de fezes bovinas como fonte de matéria orgânica e o grupo experimental. São Paulo. 1991.

\begin{tabular}{|c|c|c|c|c|c|c|c|c|c|c|c|}
\hline \multirow{2}{*}{ 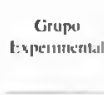 } & \multirow{2}{*}{ 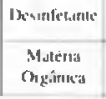 } & \multicolumn{2}{|c|}{$1: 1 \mathrm{~h}$} & \multicolumn{2}{|c|}{1332} & \multicolumn{2}{|c|}{ 1:04 } & \multicolumn{2}{|c|}{$1: 12 \mathrm{~K}$} & \multicolumn{2}{|c|}{$1.29 \mathrm{~h}$} \\
\hline & & Vikn & Sim & Nite & stm & Nikn & Sim & $\mathrm{N}_{j u s}$ & Sim & N.sh & Sim \\
\hline \multicolumn{2}{|l|}{1} & 10101,011 & $4(x,(1))$ & $\mid(x),(1)$ & $73,(x)$ & 8.1 .146 & .38 .100 & 89.50 & $\mid x, 101$ & $32,+10$ & $|x, 0| 1$ \\
\hline \multicolumn{2}{|l|}{2} & $\mid 00,(0)$ & $4 \times .201$ & $2 n, 1 \times 1$ & XK, (XI & $70,(M)$ & $1 \times, 211$ & 20.060 & 70.10 & 3,100 & $(41,50)$ \\
\hline \multicolumn{2}{|l|}{1} & $\mid\{H\},(W\}$ & पx, (n) & 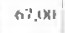 & "26, 111 & $x \leq \leq 0$ & 81.70 & $x ! \cdot 4)$ & 60.50 & 18.90 & $39,110)$ \\
\hline \multicolumn{2}{|l|}{\rfloor} & $($ (K) $(\mathrm{CH})$ & (x) sI & प्र..811 & M1.7\| & $x \geq 311$ & 6. 1.410 & ע5.20 & (5.70) & $30 .(15)$ & $|\cdot| \cdot(N)$ \\
\hline \multicolumn{2}{|l|}{ s } & $(\mid(n),(w)$ & 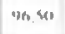 & (4) Sus & (XX,k1) & $x \leq(1, y)$ & $x 7 .(x)$ & $82 .(x)$ & 72.50 & $2-4.10 \mathrm{~m})$ & 29.20 \\
\hline \multicolumn{2}{|l|}{$\begin{array}{l}\text { Movilat } \\
\text { Animéthad }\end{array}$} & $\mid(x),(1))$ & 47.36 & $\times 9, e n$ & $x ?, 40$ & $x(1, x 2$ & 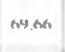 & as, 1: & AI. 100 & 35,600 & $32.2 n$ \\
\hline \multicolumn{2}{|l|}{$\begin{array}{l}\text { [kw161 } \\
\text { Pulrik1 }\end{array}$} & & 1.31) & 18.58 & $4.4 ?$ & 5.5 & $13, \mathrm{hat}$ & 8.43 & 18.45 & 17.46 & Its.51 \\
\hline \multicolumn{2}{|l|}{ c 1} & $=$ & 1.12 & 15,19 & $10, \times 10$ & $n, \times 1$ & 34,25 & 10,1.12 & 21,54 & S61.16 & 91.28 \\
\hline \multicolumn{2}{|l|}{ 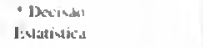 } & \multicolumn{2}{|c|}{$s$} & \multicolumn{2}{|c|}{ NS } & \multicolumn{2}{|c|}{$N S$} & \multicolumn{2}{|c|}{ S } & \multicolumn{2}{|c|}{ NS } \\
\hline
\end{tabular}

$C V=$ Coeficiente de Variabilidade de Pearson; * = Verificação da significûncia da hipótesé de nulidade para o efeito da presença da matéria orgânica, para cada concentração de hipoclorito de sódio (Teste U de Mann-Whitney $\alpha=0,05) ; S=$ Estatisticamente signilicante; NS = Fstatisticamente nāo significante.

TA BEI.A 2

Percentagem de redução de Unidades Formadoras de Colonias (U.F.C.) de Mycobacterium fortuitum em relação ao grupo controle, segundo a concentração de hipoclorito de sódio com $2,5 \%$ de cloro ativo. a condição) de (ratamento com $1,0 \mathrm{~g}$ de fezes bovinas como lonte de matéria orgânica co grupo experimental. São Paulo. 1991 .

\begin{tabular}{|c|c|c|c|c|c|c|c|c|c|c|c|}
\hline \multirow{2}{*}{$\begin{array}{c}\text { Grups } \\
\text { 1: :perimental }\end{array}$} & \multirow{2}{*}{$\begin{array}{c}\text { Ixwntetasale } \\
\begin{array}{c}\text { Yoleria } \\
\text { Onginicad }\end{array}\end{array}$} & \multicolumn{2}{|c|}{ 1:16 } & \multicolumn{2}{|c|}{ 1:12 } & \multicolumn{2}{|c|}{$1 \mathrm{~cm}$} & \multicolumn{2}{|c|}{$1: 12 \mathrm{~K}$} & \multicolumn{2}{|c|}{1248} \\
\hline & & Nink & S।ı & $N_{j u b}$ & $\operatorname{sim}$ & Xns & SimI & $N_{3 n s}$ & $s_{111}$ & Niw1 & Sun \\
\hline 1 & & $100,(0)$ & $x_{,},(k)$ & 94,211 & 45.80 & $x h,(x)$ & | fill, (K) & $(6.20)$ & $17 .(N)$ & $5 x, k 0$ & 01,100 \\
\hline 2 & & $\mid(M),(n)$ & $\mathbf{U K , I K ]}$ & $w, k \|$ & K2..30 & $\mathbf{4 x},(\mathrm{K})$ & $182 .(6)$ & 160,40 & 75,20 & $\mathrm{X} 5,(4)$ & $\left(w_{1}, \Delta\right)$ \\
\hline 3 & & 40,70 & (א).30 & 42,70 & $(H, 20$ & $8(1,20)$ & (f), 26 & $S \varsigma, k()$ & $n 0,30$ & $\$ S, \mathrm{KO}$ & 9.51 \\
\hline 4 & & 100,040 & 72.20 & $9 \times, 411$ & 72.20 & X). (n) & 72.20 & 1100,00 & $5(0.16)$ & $7 \times .90$ & | $1 . . k 1$ \\
\hline 5 & & 1000.00 & $H_{1}, K(0)$ & 97.511 & $74 . \mathrm{KII}$ & $79,00)$ & 70,50 & $\times 3.91$ & Q7.1K) & $x \geq \ldots 31$ & All.|XI \\
\hline $\begin{array}{c}\text { Médis } \\
\text { sntméticias }\end{array}$ & & 09,94 & 86.54 & 97.92 & 67.86 & 85.96 & 69.70 & 74.42 & $5+.111$ & $72.0 \mathrm{k}$ & 26.14 \\
\hline $\begin{array}{l}\text { Dessio } \\
\text { Padran }\end{array}$ & & & 10.48 & 2.53 & 12,45 & 0.7 .4 & 0.3 .3 & $2 \cdot b, 9,1$ & 20.02 & 12.27 & 24.04 \\
\hline $\mathrm{cv}$ & & & 12.57 & 2.54 & $1 \times, 14$ & 7.67 & 4.06 & איא.9. & 37.60 & 17.04 & 92.15 \\
\hline $\begin{array}{l}\text { - Decisbas } \\
\text { Estatistica }\end{array}$ & & s & & & & & 5 & & & & $\mathbf{s}$ \\
\hline
\end{tabular}

CV = Coeficiente de Variabilidade de Pearson; * = Verificação da significância da hipótese de nulidade para o efeito da presença da matéria orgânica. para cada concentraçāo de hipoclorito de sódio (Teste L' de Mann-Whitney $\alpha=0.05$ ) : $S=$ Fstatisticamente significante.

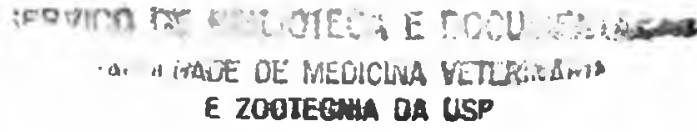

E ZOOTEQAH OA USP 


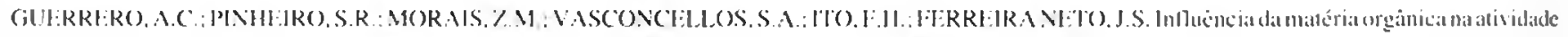

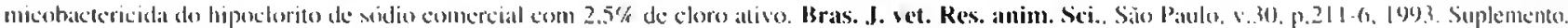

\section{TABEIA 3}

Percentagem de redução de Unidades Formadoras de colônias (L.1:(C) de Mycobacterium fortuitum em relação au grupo controle, segundes a concentraçä́o de hipoclorito de sóxlio com $2.5 \%$ de cloro ativo, a condiçäo de tratamente com 1.5 g de lexes bovinas

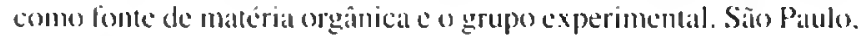
1991 .

\begin{tabular}{|c|c|c|c|c|c|c|c|c|c|c|c|}
\hline \multirow{2}{*}{$\begin{array}{c}\text { Grups } \\
\text { Eypenimental }\end{array}$} & \multirow{2}{*}{$\frac{\text { Desinfetanie }}{\overline{\text { Materia }}}$} & \multicolumn{2}{|c|}{$1: 16$} & \multicolumn{2}{|c|}{132} & \multicolumn{2}{|c|}{100} & \multicolumn{2}{|c|}{$1: 12 x$} & \multicolumn{2}{|c|}{1.256} \\
\hline & & $\mathrm{Nbo}$ & Sim & $\mathrm{NBn}$ & Sim & $\mathrm{Nb}$ & Sam & Náo & Sim & $\mathrm{Ngo}$ & Sim \\
\hline \multicolumn{2}{|l|}{1} & 100,00 & 99,101 & 100,01 & $9 \times, \times 0$ & 93,201 & $75, \mathrm{k0}$ & 90.100 & 45,00 & $73,(60)$ & 19.30 \\
\hline \multicolumn{2}{|l|}{2} & 100.00 & 81,00 & 99.00 & 63,40 & 92.80 & 80.00 & 68.20 & 3,00 & 3.50 & 21.90 \\
\hline \multicolumn{2}{|l|}{3} & 100.00 & 99.00 & 80.00 & $\$ 1.00$ & 93,00 & 69.60 & 62.20 & 11.30 & 31,30 & 7,90 \\
\hline \multicolumn{2}{|l|}{4} & 100,00 & 89.60 & 92,00 & 75,30 & 80.20 & $75.3 \mathrm{n}$ & 60.50 & 28,70 & 90,00 & 4,00 \\
\hline \multicolumn{2}{|l|}{5} & 99.80 & 87,80 & 93.30 & 70.70 & 81.70 & 63,40 & 65.20 & 39.00 & 98.30 & 29.20 \\
\hline \multicolumn{2}{|l|}{$\begin{array}{c}\text { Métia } \\
\text { Antemetica }\end{array}$} & 99,96 & 91,42 & 93,86 & 77.84 & 88.16 & 72.82 & 70.42 & 25,80 & 67,74 & 16,38 \\
\hline \multicolumn{2}{|l|}{$\begin{array}{l}\text { Desvio } \\
\text { Padrae }\end{array}$} & 0.08 & 6.71 & 6.43 & 11.90 & 5.95 & 5.75 & 13,05 & 15.45 & 33.55 & 9,33 \\
\hline \multicolumn{2}{|l|}{ c. V } & $0.0 \mathrm{~s}$ & 733 & $6, \times 5$ & 15,28 & 6.71 & 7.89 & 18,53 & 59,88 & 49.53 & 56.95 \\
\hline \multicolumn{2}{|l|}{$\begin{array}{l}\text { - Decinbo } \\
\text { Ftatistica }\end{array}$} & \multicolumn{2}{|c|}{5} & \multicolumn{2}{|c|}{ S } & \multicolumn{2}{|c|}{ s } & \multicolumn{2}{|c|}{$S$} & \multicolumn{2}{|c|}{ NS } \\
\hline
\end{tabular}

CV = Coeficiente de Variabilidade de Pearson; * = Verificação da significância da hipótese de nulidade para o efeito da presença da matéria orgânica, para cada concentraçāo de hipoclorito de sódio (Teste $\mathrm{U}$ de Mann-Whitney $\alpha=0.05) ; S=$ Fstatisticamente significante; $N S=$ Estatisticamente não significante.

\section{TABI:LA 4}

Percentagem de redução de Unidades Formadoras de Colônias (U.F.C.) de Mycobacterium fortuitum com relaçio ao grupo conIrole, segundo a concentração de hipoclorito de sódio eom $2,5 \%$ de cloro attivo, a condição de tratamento com $2.0 \mathrm{~g}$ de feses bovinats como lonte de matéria orgânica cio grupo experimental. São P'atulo. 1901.

\begin{tabular}{|c|c|c|c|c|c|c|c|c|c|c|c|}
\hline \multirow{2}{*}{$\begin{array}{c}\text { Girupo } \\
\text { Fipelimental }\end{array}$} & \multirow{2}{*}{\begin{tabular}{|c|} 
Decinfetanie \\
Matena \\
Urghica
\end{tabular}} & \multicolumn{2}{|c|}{1.16} & \multicolumn{2}{|c|}{$1: 32$} & \multicolumn{2}{|c|}{164} & \multicolumn{2}{|c|}{$1: 128$} & \multicolumn{2}{|c|}{$1: 256$} \\
\hline & & NEs & Sim & Nìo & Sim & Nin & Sim & Nin & Sim & Nono & Sim \\
\hline 1 & & 100.00 & 96.00 & 100,00 & 72,30 & 97,00 & 72.30 & 50,00 & 61,20 & 90.00 & 44,50 \\
\hline 2 & & 100.00 & 78.60 & 96.80 & 45.80 & 84.50 & 65.80 & 70.00 & 72.50 & 70.00 & 0.00 \\
\hline 3 & & 100.00 & 97.20 & 79.30 & 57,00 & 92,20 & GA,20 & 57,80 & 46,40 & 40.00 & 38.00 \\
\hline 4 & & 100,00 & 59.00 & 99.00 & 70,40 & 94.70 & 54.50 & 99,00 & 24,20 & 34,20 & 42,40 \\
\hline 5 & & 100.00 & $\mathbf{R 8 , 4 0}$ & 97,50 & 69,30 & 62,80 & $7 \triangleleft, 40$ & 83,50 & 9,00 & 65.70 & 13.60 \\
\hline $\begin{array}{l}\text { Médid } \\
\text { Aritmelica }\end{array}$ & & 100,00 & 83,84 & 94,52 & 62,96 & 88.24 & $\Delta f, 24$ & 72,00 & 42,66 & 59.98 & 27.70 \\
\hline $\begin{array}{l}\text { Desvio } \\
\text { Patrito }\end{array}$ & & & 39.68 & 7.64 & 10.12 & 12,45 & 7.01 & 17,61 & 23.33 & 20.48 & 17.72 \\
\hline c. $\mathbf{v}$. & & & 47,32 & 8.13 & 16.07 & $14,4]$ & 10.57 & 24,46 & 54,69 & 34,15 & 63.97 \\
\hline $\begin{array}{l}\text { - Decisua } \\
\text { Pinatiuxa }\end{array}$ & & $s$ & & $s$ & ; & 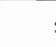 & & & & & S \\
\hline
\end{tabular}

CV = Coeficiente de Variabilidade de Pearson; * = Verificação da significância da hipótese de nulidade para o efeito da presença da matéria orgânica, para cada concentração de hipoclorito de sódio (Teste $U$ de Mann-Whitney $\alpha=0,05) ; \quad S=$ Estatisticamente significante; NS = Estatisticamente nāo significante. a 2.0 gramas de matéria orgânicaa (Tah. 4), já ć observado pelo menos um percentual cle redução inferior a $70 \%$ na diluição do hipoclorito de sódio de l:16 (grupo experimental 4).

As Tab. 1 a 4 possibilitam a análise da variaçajo observada nos resultados obtidos com a me lodologia experimental empregada. De fato. para as concentraçós de hipeclorito de sódio de 1:128 e 1:256. são observaldos coeticientes de variação superiores a $30 \%$ com valores mais elevados quando em presençąa de matéria orệinicial.

\section{DISCISSÃo}

As Tab. I a 4 construídas com os resultados obtidos pelo cálculo dos percentuais de redução das contagens de U.F.C. em relaçajo aos controles demonstraram yute para ser mantido IIIn mínimo de $70 \%$ de redução de microrganismos, a presenfal de matéria orgânica delermina a necessidade de pelo menos quatro veyes mais desinfelante. Realmente, considerando-sc o valor de $70 \%$ como o mínimo accitátel em termos de eficaicia do produto químico. encontra-se para o hipoclorito de sódio com 2.5\% de cloro ativo als diluiçóes de trabalho de $1: 64$ e $1: 16$, respectivamente para als condiçōes de ausència ou de presença de matéria orgânică.

Os resultados do presente trabalho concordalun com os observados por PINHEIRO ${ }^{\text {wo }}(1990)$ quando da avaliaçio do mesmo tipo de desinfetante na diluição de $1: 8$ frente a 0.5 grama de fezes de bovino como fonte de matéria orgánica. Do exposto, pode-se depreender que para este nivel de componente orgânico a maior diluição de trabalho do hipoclorito de sódio com 2.5\% de cloro ativo é a de 1:16. Tais observaçóes são igualmente concordantes com as obtidas em outros ensaios ${ }^{8,7,11,1218}$, que também admitiram a cxistência de uma inlluência negativa da matéria oroânica sobre a atividade bactericida dos hipocloritos. Entretanto, cumpre ser salientado que tais atïrmaçōes discordam da lcoria da atividade desinfetante das cloraminas que pressupõe a persistência do poder bactericida docloro ligado aos compostos nitrogenados existentes nos diversos tipos de matéria orgânica".

O elevado coeliciente de variação constatado nos ensaios que empregaram as mais altas diluiçóes do hipoclorito de sódio sugere que a partir de um dado valor de concentração do desinfetante o seu efeito micobactericida começa a comportar-se de mancira muito irregular. () mesmo tipo de perfil foi obtido por PINHEIRO ${ }^{16}(1990)$ quando testou o cfeito micobactericida de um iodóforo na diluição de trabalho de $1: 250 \mathrm{v} / \mathrm{v}$.

A irregularidade nat atividade micobacteriana do desinfetanIc. constatada a partir do cálculo dos coeficientes de variação, 


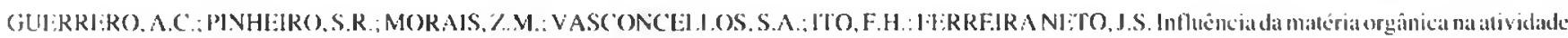

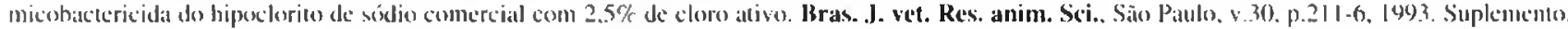

além de revelar associação com as maiores diluiçōes do desinfetante químico, também apresenta relação com o atumento dos niveis de matéria orgânica. o que fïca bastante evidente yuando da observaçăo dos valores indicados na Tab. 4 onde. frente a 2,0 gramas de matéria orgânica, é encontrado um coeficiente de variação de $47,32 \%$ para o hipoclorito de sídio diluido na proporção de $1: 16$.

A temperatura escolhida para a realização dos testes $\left(4\right.$ a $8^{\circ} \mathrm{C}$ ) É uma condição que coloca o produto em um nível crítico pois. simulando um valor vigente nos meses de inverno en regiōes de clima temperado, são obtidas conclusieses que poderão ser melhoradas caso a avaliação venha a se realizar em temperaturas mais elevadas, ustuais nas outras estaçōes do ano em tais áreas e durante lodo o ano em regiōes de clima tropical esubtropical.

Os resultados obtidos demonstraram que quando da escolha do hipoclorito de sódio como alemento auxiliar em progralmas de controle da tuberculose bovina, o seu emprego a nivel de instalaçōes e de equipamentos zootécnicos deverá ser sempre precedido de uma completa higienização visando a remoção dos componentes orgânicos.

\begin{abstract}
SUMMARY
It was evaluated the highes working dilution of the sodium hypochlorite solution (available as household and laundry bleach, with $2.5 \%$ of active chlorine) still effective in inactivating Mycobacterium fortuitum in the presence of different levels of hovine feces as organic soil. The experiments were conducked "in vitro" using filter paper als carriers. The time of contact was one hour at the lemperature range of $+108^{\circ} \mathrm{C}$. The blecking of the desinfectant anctivity was achicved by the dilution using a solution of $0.5 \%$ sodium thiosulphate with $0.05 \%$ (wenn- 80 $(v / v)$. The remaining microrganisms were cultivated in l.owensicin-Jensen culture medium and the number of colonies forming unities was statiscally evalualled by the Mann Whitney'test. The results showed that the organic soil affected the desinfectant activity. The working dilutions calculated were $1: 64$ and $1: 16$. respectively. with and without organic soil. In working dilutions higher than $1: 64$ the regularity of the desinfectant action was very poor.
\end{abstract}

UNTERMS: Desinfection; Mycobacteria: Soxlim hypochloric

\section{RFFERF̂NCIAS BIBLIOCRÁFICAS}

()!-AI.TH:RTHLM. F:: TIMH:NETSKY, V. Antissépticos e desinfetantes. In : ZANINI, A.C.: OCiA, S., ed. Farmacologia aplicada. 4. ed. São Pauto, Atheneu, 1989. p.58.3-99.

02-CH.VTRO PA.NA.MH:RICA.NO DE ZOONOSIS. Manual de normas y procedimentos técnicos para la bacteriologia de la tuberculosis. Bucnos aires, 1985. (. Vota técnica, 27)

0.3-CHICK, II.; MAR I'I.V, C.J. The principles involved in the standardization of disinfectants and the influence of organic matter-upon germicidae valuc. J. Hyg., L .odon, v.8. p.6.55-97. 1908.

04-COSTA, D.K.M. Desintetantes em saúde animal. Bol. Def. sanit. anim., p.1-54. 1987. Número especial.

05-COSTIGAN, M.S. Elfectiveness of hot hypochlorites of low alkalinity in destroying Mycobacterium tuberculosis. J. Bacteriol., v.32, p.57-6.3, 1936.
06-DYCHI)AL A, G.R. Chlorine and Chlorinc compounds. In: BL()CK, S.S.. cd. Disinfection sterilization and preservation. 3 ed. Philadelphia. L.eal \& Febiger. 1983. p.157-82.

07-FIN(H, W.L. Disinfectants their values and uses. l.ondon. Chapman \& Hall, 1958. p.120)-8.

OR-GÉL.INAS. P.: GOUL.ET, J. Neutralization ol the activity of eight disinfectants by organic matter. J. appl. Bacteriol., v.54, p.243-7, 1983

(9)-HL:KMATI, M.; BRADI.IYY JUNIOR, R.I. liftecl of milk constituents on the persistence of sodium hypochlorite sanitizer. J. dairy Sci., v.62, p.47-8, 1979.

10-HOFPMAN, P.N.; DHATH, J.L:; COATIS, I). The stability of sodium hypoclorite solutions. In: COL.I.INS. C.H.: AL.LOWOOD, D.M.C.; BL.OOMFIELD, S.F.; $\mathrm{F} O \mathrm{OX}, \mathrm{A}$., ed. Disinfectants their use and evaluation of effectiveness. New York, Academic press, 1981. (Society for Applied Bacteriology Technical Series, 16) 
GLERRERO, A.C.; PINIIEIRO, S.R.: MORAIS.Z.M.: VASCONCELLOS.S.A.: ITO,F.H.; FERREIRA NETO, J.S. Intluência da matérial orgânica na attividade micobactericida do hipoclorito de sódio comercial com 2.5\% de cloro ativo. Bras. .l. vet. Res. anim. Sci.. Sáo Paulo, v.30, p.211-6. 1993. Suplemento.

11-JONES, L.M.: BOOTH, N.H.; McDONALD, L.E. Farmacologia e terapêutica em veterinária. 4. cd. Rio de Janeiro, Guanabara Koogan, 1983. p.620-43.

12-LINTON, A.H.; HUGO, W.B.; RUSSEL, A.D., eds. Disinfection in veterinary and farm animal practice. Oxford, Black-well Scientilic Publications, 1987. p. 178.

13-MARKS, H.C.; WYSS, O.; STRANDSKOV, F.B. Studies on the mode of action of compounds containing available chlorine. J. appl. Bacteriol., v.49, p.299$305,1945$.

14-MASAKI, S.; SHIMIZU, K.: CHO. N.: HIROSE, T. Isolation of mycobacteria from lymphonodes of pigs and their environment. Jap. J. vet. Sci., v.44, p.213$21,1982$.

15-PELCZAR, M.; REIDR; CHAN, E.C.S. Microbiologia: controle dos microrganismos, controle por agentes químicos. São Paulo, Mc Graw Hill do Brasil, 1980. v.1, p.493-516.

16-PINHEIRO, S.R. Influência da matéria orgânica na atividade micobactericida de cinco desinfetantes químicos de uso pecuário. São Paulo, 1990. Dissertação (Mestrado) - Faculdade de Medicina Veterinária c Zootecnia, Universidade de São Paulo.

17-RLBIN. J. Agents for disinfection and control of tuberculosis. In: BLOCK, S.S. Disinfection, sterilization and preservation. 3. ed. Philadelphia, Lea \& Febiger, 1983. p.414-21.

18-RUSSEL, A.D. Factors influencing the efficacy of antimicrobial agents. In: RUSSEL, A.D.; HUGO, W.B.: AYLIFFE, G.A.J., eds. Principles and practices of disinfection, preservation and sterilisation. London, Blackwcll, 1982. p.107-33.
19-SAURAT, M.M.P.; LAUTIÉ, R. De l'action de quelques disinfectants sur le baccille tuberculeaux. Rev. Méd. vét., Toulouse, v.111, p.186-99, 1960).

20-SIEGEL, S. Estatística não paramétrica (para as ciências do comportamento). São Paulo, McGraw-Hill, 1975.

2I-SMITH, 1968 apud RUBIN ${ }^{17}, 1983$, p.419.

22-SOUNIS, E. Biocstatística: princípios fundamentais. metodologia estatística, aplicação às ciências biológicas. Sāo Paulo, McGraw-Hill do Brasil, 1972. p.230.

23-SUSAN, C.; MORGAN. J. Cleaning and disinfection of farm buildings. In: COLLINS, C.H.; ALLOWOOD. D.M.C.; BLOOMFIELD, S.F.; FOX, A., eds. Disinfectants their use and evaluation of effectiveness. New York. Academic Press, 1981. (Society for Applied Bacteriology Technical Series. 16)

24-VERA, A.; VOLKOVSKY, G.; SANCHEZ, I.; COTRINA. N. Acción de desinfectantes contra M. bovis : hidróxido de sódio, mezcla de este producto con formaldehido, productos clorados y ácido peracético. Cienc. Tec. Agric. Vet., v.7, p.29-38, 1985.

25-WANG, W.L.; POWERS, B.W.: LUECHTEFELD, N.W.: MARTIN, J. Effects of disinfectants on Campylobacter jejuni. Appl. environ. Microbiol., v.45, p.1202-5, 1983.

26-WORLD HEALTH ORGANIZATION. Guidelines on disinfection in animal husbandry for prevention and control of zoonotic diseases. Geneva, 1984. (WHO/VPH/84.4)

Recebido para publicação em 06/08/92 Aprovado para publicação em 05/02/93 